\title{
Coberturas do Solo sobre a Amplitude Térmica e a Produtividade de Pimentão ${ }^{1}$
}

\author{
The Effect of Soil Covers on Temperature Range and Yield of Sweet Pepper \\ COELHO, M.E.H. ${ }^{2}$, FREITAS, F.C.L. ${ }^{3}$, CUNHA, J.L.X.L.. ${ }^{4}$, SILVA, K.S. ${ }^{5}$, GRANGEIRO, L.C. ${ }^{6} \mathbf{e}$ \\ OLIVEIRA, J.B. ${ }^{2}$
}

\begin{abstract}
RESUMO - Com o objetivo de avaliar o efeito dos sistemas de plantio direto e convencional e estratégias de manejo de plantas daninhas na variação da temperatura do solo e na produtividade de pimentão, realizou-se, na Universidade Federal do Semiárido, em Mossoró$\mathrm{RN}$, um experimento no esquema de parcelas subdivididas, distribuídas no delineamento experimental em blocos casualizados com quatro repetições. Os sistemas de plantio direto e convencional do pimentão foram avaliados nas parcelas; nas subparcelas, avaliaram-se três estratégias de manejo de plantas daninhas (cobertura do solo com filme de polietileno preto, com capinas e sem capinas). Em cada subparcela foram instalados sensores tipo termopares, a $5 \mathrm{~cm}$ de profundidade, para medir a temperatura do solo. A partir dos dados obtidos, determinou-se a variação da temperatura ao longo do dia, no período de 20 a 30 dias após o plantio das mudas de pimentão, e a cada cinco dias, a média das temperaturas máxima e mínima e a amplitude térmica diária. Aos 60 e 147 dias após o transplante das mudas de pimentão, foram feitas avaliações da densidade e massa seca de plantas daninhas nos tratamentos sem capinas. Os tratamentos com filme de polietileno e capinado no sistema de plantio convencional apresentaram elevação na temperatura máxima diária do solo em 6,7 e $5,0{ }^{\circ} \mathrm{C}$, respectivamente, em relação ao sistema de plantio direto com capinas. A amplitude térmica no sistema de plantio convencional nos tratamentos com capinas regulares e com filme de polietileno foi de $11^{\circ} \mathrm{C}$, ao passo que no sistema de plantio direto a amplitude foi de 6,3, 4,5 e 4,0 ${ }^{\circ} \mathrm{C}$ nos tratamentos com capinas, sem capinas e com filme de polietileno, respectivamente. A interferência das plantas daninhas nos tratamentos sem capinas resultou em redução de 94,95 e 92,10\% da produtividade comercial nos sistemas de plantio direto e convencional, respectivamente.
\end{abstract}

Palavras-chave: Capsicum annuиm, temperatura do solo, filme de polietileno, cobertura morta, plantio direto.

\begin{abstract}
To evaluate the effect of the no-tillage and conventional systems, weed management strategies on soil temperature variation, and yield of sweet pepper, a field experiment was arranged in a randomized block split-plot design with four replications. Tillage systems (no-tillage and conventional) were evaluated in the plots, and three weed management strategies in the split-plots (soil cover with black polyethylene film, with weeding, and without weeding). At 60 and 147 days after transplanting (DAT), density and dry mass of the weeds were assessed in the treatments without weeding. In each split-plot, thermocouple type sensors were installed at $5 \mathrm{~cm}$ depth to measure soil temperature. Based on the data obtained, temperature variation along the day was determined from 20 to 30 days after planting the sweet pepper seedlings, while the mean maximum and minimum temperatures and temperature range were evaluated every five days. The treatments with polyethylene film and clean weeding under the conventional tillage system showed an increase in maximum daily soil temperature at 6.7 and $5.0^{\circ} \mathrm{C}$, respectively, compared to no-tillage and weeding. The temperature range was $11^{\circ} \mathrm{C}$ in the treatments using polyethylene film and clean weeding
\end{abstract}

Recebido para publicação em 10.7.2012 e aprovado em 17.11.2012.

Prof., Instituto Federal do Ceará, Campus Iguatu, <mehcoelho@yahoo.com.br>, <joaquimbrancodeoliveira@hotmail.com>; ${ }^{3}$ Professor, Dep. de Ciências Vegetais, Universidade Federal Rural do Semiárido - UFERSA, <fclaudiof@yahoo.com.br $>$; ${ }^{4}$ EngoAgr ${ }^{0}$., Universidade Federal de Alagoas, <cunhajlx@gmail.com >; ${ }^{5}$ Doutoranda em Fitotecnia, UFERSA, <kaliane_kaka@hotmail.com>; ${ }^{6}$ Professor, Dep. de Ciências, UFERSA, <leilson@ufersa.edu.br>. 
under the conventional system, $6.3^{\circ} \mathrm{C}$ under no-tillage with weeding, $4.5^{\circ} \mathrm{C}$ in the treatments without weeding, and $4.0^{\circ} \mathrm{C}$ under no-tillage with polyethylene film. The no-tillage system proved to be a good technique for the cultivation of sweet peppers under high temperature conditions. Weed interference in the treatments without weeding resulted in a reduction of $94.95 \%$ and $92.10 \%$ of marketable yield underno-tillage and conventional systems, respectively

Keywords: Capsicum annuum, soil temperature, polyethylene film, mulch, no-tillage.

\section{INTRODUÇÃO}

A temperatura do solo está relacionada com os processos de interação solo-planta, destacando-se o desenvolvimento e a atividade das raízes em absorver água e nutrientes do solo (Gasparim et al., 2005). A cultura do pimentão, em algumas épocas do ano, tem a sua produção comprometida, devido a temperaturas extremas do solo, que alteram o ciclo da cultura e o crescimento dos frutos (Lorentz, 2004). Para o bom desenvolvimento e crescimento das plantas de pimentão, o ideal é que a temperatura do solo esteja torno de $17^{\circ} \mathrm{C}$; acima de $30{ }^{\circ} \mathrm{C}$, há redução do crescimento radicular e abortamento das flores (Pádua et al., 1984).

A cobertura do solo com material inorgânico ou orgânico tem sido utilizada com o intuito de protegê-lo das adversidades climáticas e é capaz de modificar o regime térmico do solo, tanto aumentando quanto diminuindo a sua temperatura em função da espessura e das propriedades térmicas dos materiais utilizados na cobertura, contribuindo para manutenção da temperatura e umidade do solo em niveis adequados para o desenvolvimento das plantas (Gasparim et al., 2005; Resende et al., 2005).

No cultivo de hortaliças, a cobertura do solo com filme de polietileno tem sido bastante utilizada no controle de plantas daninhas e na redução da perda de água por evaporação. Teófilo et al. (prelo...) verificaram que o solo coberto com filme de polietileno aumentou a eficiência do uso da água na cultura do melão, em relação ao solo sem cobertura.

No entanto, essa prática eleva a temperatura do solo, tornando-a sempre superior à do solo descoberto (Bonanomi et al., 2008); em condições de alta temperatura, como na região
Nordeste do Brasil, esse aumento pode prejudicar o desenvolvimento das culturas. Segundo Furlani et al. (2008), temperaturas do solo muito altas têm efeitos negativos sobre plântulas e raízes e na atividade microbiana do solo, podendo comprometer também a absorção de nutrientes pelas plantas (Carvalho et al., 2005).

A cobertura do solo com material orgânico de origem vegetal - um dos princípios do plantio direto - constitui-se em uma barreira física, evitando a incidência direta da radiação solar, diminuindo a transferência de energia e vapor de água para a atmosfera e reduzindo a magnitude das oscilações diárias da temperatura do solo, principalmente próximo à superfície (Gasparim et al., 2005), além de minimizar a erosão superficial e diminuir a infestação de plantas daninhas; estas, quando não controladas e dependendo da infestação, podem propiciar perdas significativas na produtividade do pimentão (Souza et al., 2008).

Ibarra-Jiménez et al. (2008) e Moura Filho (2009), trabalhando com as culturas do pepino e alface, verificaram que a cobertura do solo com polietileno proporcionou elevação da temperatura do solo em 5,2 e $4,0{ }^{\circ} \mathrm{C}$, respectivamente, em relação ao solo com cobertura morta. Diversos outros autores têm constatado menor temperatura do solo quando se utiliza o sistema de plantio direto, em comparação com o plantio convencional (Resende et al., 2005; Levien et al., 2005; Furlani et al., 2008).

Diante do exposto, realizou-se esta pesquisa com o objetivo de avaliar a variação da temperatura do solo e a produtividade de pimentão em função de estratégias de manejo de plantas daninhas nos sistemas de plantio direto e convencional. 


\section{MATERIAL E MÉTODOS}

O experimento foi realizado na horta didática do Departamento de Ciências Vegetais da Universidade Federal Rural do Semiárido (UFERSA), no município de Mossoró-RN, localizado a $5^{\circ} 11^{\prime} 15^{\prime \prime}$ de latitude sul e 37'20’39" de longitude oeste e $18 \mathrm{~m}$ de altitude. O clima da região, de acordo com a classificação de Köppen, é do tipo BSwh", quente e seco, com precipitação pluvial média anual de $673,9 \mathrm{~mm}$, temperatura e umidade relativa do ar média de $27{ }^{\circ} \mathrm{C}$ e $68,9 \%$, respectivamente; o período chuvoso na região é de fevereiro a junho, com baixíssima possibilidade de ocorrência de chuvas entre agosto e dezembro (Carmo filho \& Oliveira, 1995).

Utilizou-se o esquema de parcelas subdivididas, distribuídas no delineamento experimental em blocos casualizados, com quatro repetições. Os sistemas de plantio direto do pimentão (SPD) e convencional (SPC) foram avaliados nas parcelas, em áreas anteriormente cultivadas nos respectivos sistemas durante quatro anos. As subparcelas foram formadas por três estratégias de manejo de plantas daninhas (cobertura do solo com filme de polietileno preto, com capinas regulares e sem capinas). Cada unidade experimental foi composta por três fileiras de $12 \mathrm{~m}$ espaçadas entre si de $0,90 \mathrm{~m}$, com plantas espaçadas de $0,60 \mathrm{~m}$ nas fileiras. Foi considerada área útil a fileira central, descartando-se duas plantas em cada extremidade.

Nos tratamentos com plantio direto, para obtenção da palhada, foi realizado em fevereiro de 2010, assim que iniciou o período chuvoso, o plantio da cultura do milho, em consórcio com Brachiaria brizanta cv. Marandu. A semeadura da forrageira foi realizada na linha do milho, misturada com adubo. Após a colheita do milho, no final de maio, a forrageira cresceu livremente até o mês de julho, quando foi feita a dessecação com $1,9 \mathrm{~kg} \mathrm{ha}^{-1}$ do herbicida glyphosate, para formação da palhada, quantificada por meio de amostragens, verificando-se 6,0 t ha ${ }^{-1}$ de massa seca.

Nas parcelas com plantio convencional, a área também foi cultivada com milho no mesmo período, e o solo foi preparado por meio de uma aração e duas gradagens, realizadas uma semana antes do transplante das mudas de pimentão.

Da área onde foi realizado o experimento foram retiradas, para cada sistema de plantio, amostras de solo na profundidade de 0 a $20 \mathrm{~cm}$ para análise química e física. O solo foi classificado como Argissolo Vermelho-Amarelo Eutrófico (Embrapa, 2006) e apresentava a seguinte granulometria: areia total = $0,88 \mathrm{~kg} \mathrm{~kg}^{-1}$; silte $=0,08 \mathrm{~kg} \mathrm{~kg}^{-1}$; argila $=$ $0,03 \mathrm{~kg} \mathrm{~kg}^{-1}$, ao passo que os resultados das análises químicas dos solos no sistema de plantio direto foram os seguintes: $\mathrm{pH}$ (água) $=6,2 ;$ matéria orgânica $=12,8 \mathrm{~g} \mathrm{~kg}^{-1} ; \mathrm{P}$ $=127 \mathrm{mg} \mathrm{dm}^{-3} ; \mathrm{K}^{+}=160 \mathrm{mg} \mathrm{dm}{ }^{-3} ; \mathrm{Ca}^{2+}=$ $3,40 \mathrm{cmol}_{\mathrm{c}} \mathrm{dm}^{-3} ; \mathrm{Mg}^{2+}=1,05 \mathrm{cmol}_{\mathrm{c}} \mathrm{dm}^{-3} ; \mathrm{Al}^{3+}=$ $0,10 \mathrm{cmol}_{\mathrm{c}} \mathrm{dm}^{-3} \mathrm{e}$, no convencional, $\mathrm{pH}$ (água) $=6,1$; matéria orgânica $=10,1 \mathrm{~g} \mathrm{~kg}^{-1} ; \mathrm{P}$ $=260 \mathrm{mg} \mathrm{dm}^{-3} ; \mathrm{K}^{+}=157 \mathrm{mg} \mathrm{dm}{ }^{-3} ; \mathrm{Ca}^{2+}=$ $3,65 \mathrm{cmol}_{\mathrm{c}} \mathrm{dm}^{-3} ; \mathrm{Mg}^{2+}=0,90 \mathrm{cmol}_{\mathrm{c}} \mathrm{dm}^{-3} ; \mathrm{e} \mathrm{Al}^{3+}$ $=0,075 \mathrm{cmol}_{\mathrm{c}} \mathrm{dm}^{-3}$. Os dados relativos a temperaturas máxima, mínima e média diárias do ar, velocidade do vento a $2 \mathrm{~m}$, radiação, evapotranspiração de referência (ETo) estimada pela equação Penmam-Monteith e parametrizada pela FAO (Allen et al., 2006), os indices pluviométricos e a umidade do ar durante o período experimental estão apresentados na Figura 1A, B, C e D, respectivamente.

A implantação do experimento foi realizada no dia 2 de setembro de 2010 por meio do transplante de mudas, produzidas em bandejas de poliestireno expandido com 200 células. Utilizou-se no experimento o híbrido de pimentão Atlantis.

A cultura foi irrigada por gotejamento com emissores de vazão de $1,7 \mathrm{~L} \mathrm{~h}^{-1}$, espaçados de 0,30 m. O manejo da água foi realizado com base na curva característica de água no solo para cada sistema de plantio a 15 e $30 \mathrm{~cm}$ de profundidade, e o controle da lâmina de água foi feito com base na leitura diária de dois tensiômetros instalados nas mesmas profundidades da curva, de modo a manter o solo com umidade superior a $80 \%$ da água disponivel total.

As adubações foram feitas com base na análise química do solo e nas exigências nutricionais da cultura, através de fertirrigação, utilizando-se $200 \mathrm{~kg} \mathrm{ha}^{-1}$ de N, $300 \mathrm{~kg} \mathrm{ha}^{-1}$ de $\mathrm{P}_{2} \mathrm{O}_{5}$ e $250 \mathrm{~kg} \mathrm{ha}^{-1} \mathrm{de} \mathrm{K}_{2} \mathrm{O}$, na forma de sulfato 

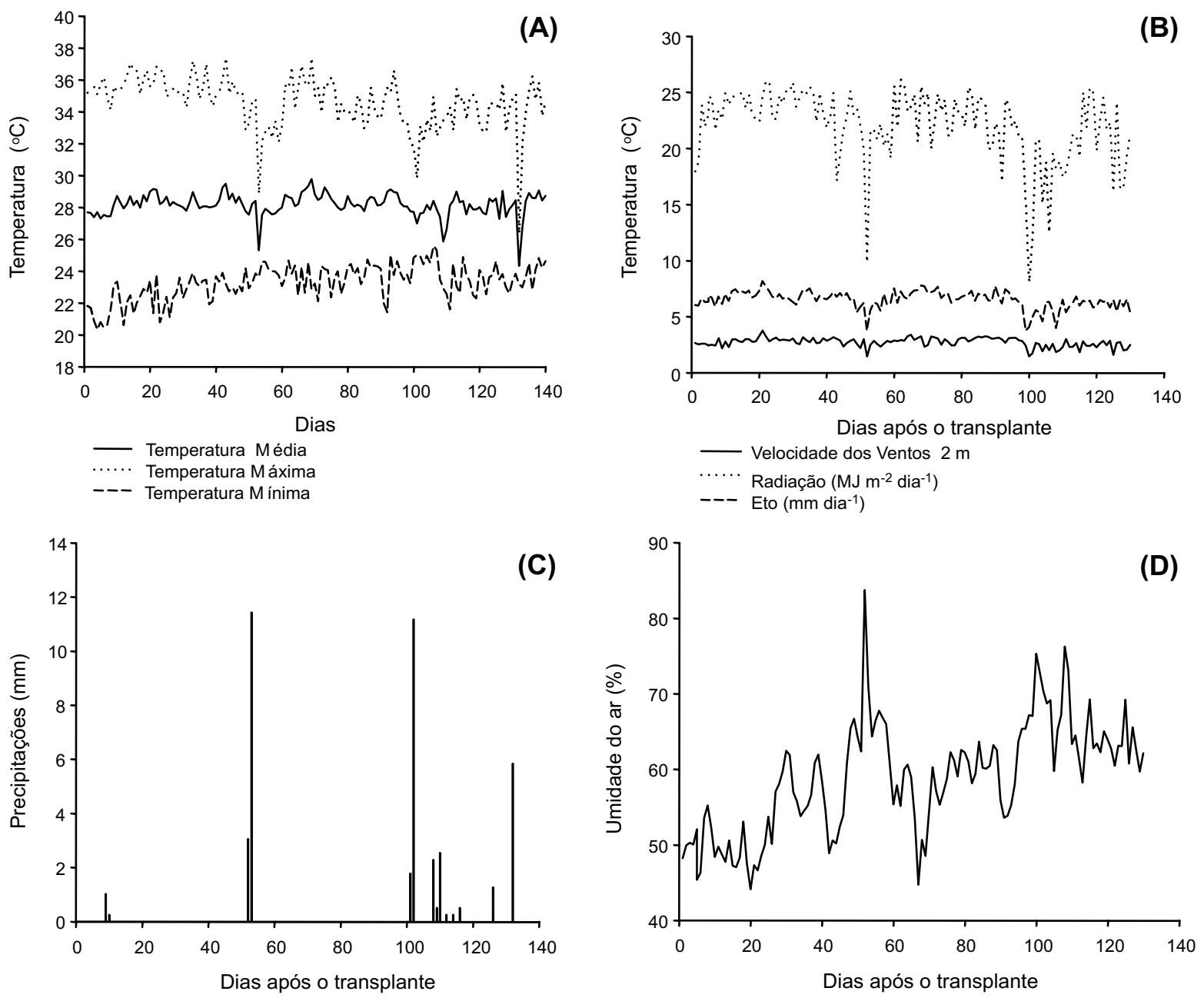

Figura 1 - Temperaturas média, máxima e mínima do ar (A), velocidade do vento a 2 m, radiação solar e evapotranspiração de referência (ETo) (B), precipitações (C) e umidade do ar (D) durante o período experimental. Mossoró-RN, UFERSA, 2010/2011.

de amônio, fosfato de monoamônio (MAP) e cloreto de potássio, respectivamente, segundo recomendações de Ribeiro et al. (1999).

As práticas culturais foram constituídas por capinas manuais, nos tratamentos com capinas, pulverizações com fungicidas e inseticidas, conforme a necessidade, com base em observações realizadas in loco. As plantas foram tutoradas utilizando-se mourões de madeira e fitilhos. Nesse caso, na extremidade de cada fileira e a cada $2,0 \mathrm{~m}$ se foi colocado um mourão; quando as plantas começaram a florescer, passou-se um fitilho de polietileno, horizontalmente ao solo, em zigue-zague duplo, ou seja, no sentido de ida e volta entre as plantas, a $15 \mathrm{~cm}$ de altura do solo. O processo foi repetido aproximadamente a cada
$30 \mathrm{~cm}$ de altura, de modo que envolvesse as plantas até o final do ciclo da cultura.

Foram instalados, em cada subparcela, sensores tipo termopares de cobre-constantan envolvidos com microtubos de polietileno para evitar a oxidação do termopar, a $5 \mathrm{~cm}$ de profundidade, a fim de medir a temperatura do solo. Os dados foram coletados a cada 10 minutos e armazenados em dataloggers Campbell CR 1000. A partir dos dados obtidos, avaliou-se, para cada intervalo de cinco dias durante o ciclo da cultura, a média das temperaturas máxima e mínima e a amplitude térmica. Determinou-se, também, a variação da temperatura do solo ao longo do dia, no período de 20 a 30 dias após o transplante (DAT) das mudas de pimentão. 
Aos 60 e 147 dias após o transplante, foram realizadas avaliações da densidade populacional e da massa seca de plantas daninhas nas subparcelas sem capinas, por meio de duas amostragens em quadrados vazados de $0,50 \mathrm{~m}$ de lado $\left(0,25 \mathrm{~m}^{2}\right)$, por subparcela. As plantas daninhas foram colhidas ao nivel do solo, contadas e levadas à estufa de circulação forçada de ar a $65^{\circ} \mathrm{C}$ até massa constante.

Na cultura do pimentão, os frutos da área útil da parcela foram colhidos semanalmente para determinação da produtividade comercial e total, sendo considerados comercializáveis aqueles com comprimento superior a $6,0 \mathrm{~cm}$ e isentos de manchas, lesões e deformações.

Os dados obtidos de produtividade foram submetidos à análise de variância pelo teste F; em caso de significância, as médias foram comparadas pelo teste de Tukey a $5 \%$ de probabilidade.

\section{RESULTADOS E DISCUSSÃO}

Nos tratamentos sem capinas, o sistema de plantio direto (SPD) apresentou, aos 60 DAT, menor densidade populacional e acúmulo de matéria seca de plantas daninhas em relação ao sistema de plantio convencional (SPC) (Figura 2A, B), o que pode ser atribuído ao não revolvimento do solo e aos efeitos físicos e/ou químicos da palhada, dificultando a germinação e a emergência das plantas daninhas. Diversos outros trabalhos também evidenciaram menor incidência de plantas daninhas no sistema de plantio direto (Tomaz, 2008; Teófilo et al., prelo ...; Silva, 2010).

Ao final do ciclo (147 DAT) observou-se redução da densidade e massa seca acumulada das plantas infestantes (Figura 2A, B). Essa redução ocorreu devido à morte de espécies de ciclo mais curto, bem como ao fato de que as plantas daninhas mais altas, como caruru-de-espinho (Amaranthus spinosus), jitirana (Merremia aegyptia) e melão-de-sãocaetano (Momordica charantia), desenvolveram-se e tornaram-se dominantes, ao passo que as mais baixas foram suprimidas e/ou morreram.

As temperaturas máximas e mínimas diárias do solo foram influenciadas pelos sistemas de plantio e pelas estratégias de manejo de plantas daninhas, com maiores valores de temperatura máxima diária, durante o ciclo da cultura do pimentão, observados no SPC com cobertura com o filme de polietileno preto, oscilando entre 39 e $42{ }^{\circ} \mathrm{C}$ (Figura 3A, B), seguido pelo tratamento mantido no limpo com capinas regulares durante todo o ciclo do pimentão, no qual foram observadas temperaturas máximas entre 38 e $41^{\circ} \mathrm{C}$.

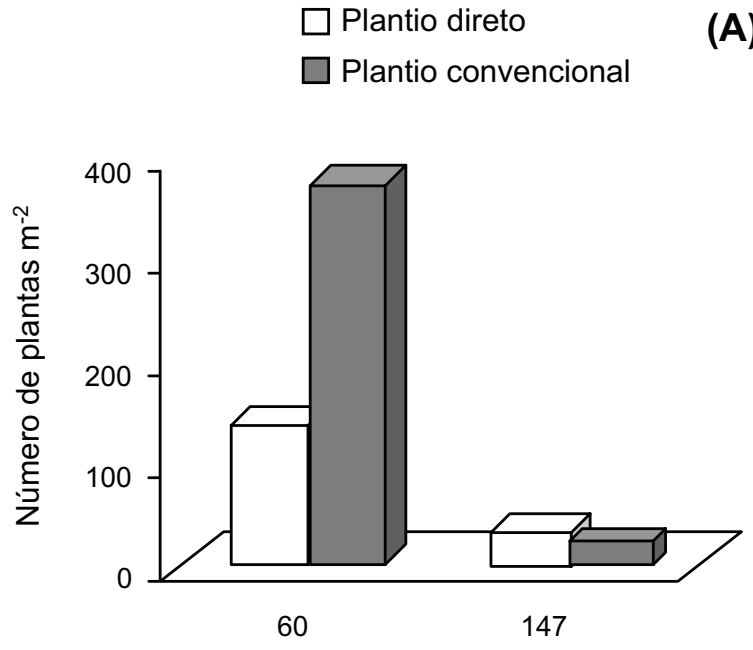

Dias após o transplante

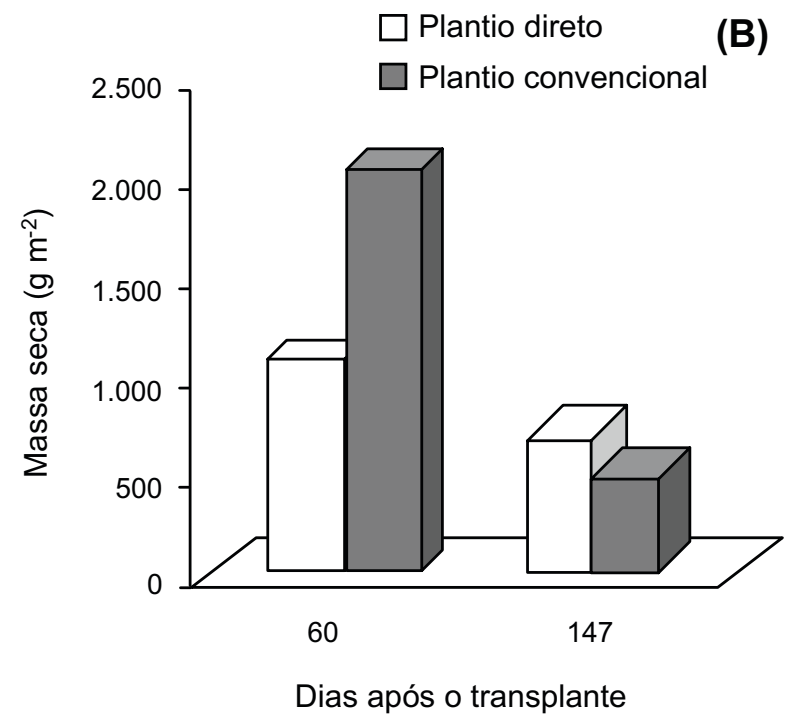

Figura 2 - Densidade de plantas daninhas (A) e massa seca de plantas daninhas (B) aos 60 e 147 dias após o transplante, em função dos sistemas de plantio e estratégias de manejo de plantas daninhas. Mossoró-RN, UFERSA, 2010/2011. 
As temperaturas máximas dos tratamentos no SPD foram inferiores às apresentadas pelo solo mantido no limpo e coberto com filme de polietileno preto no SPC, entre 31 e $35^{\circ} \mathrm{C}$ (Figura 3A). Vale ressaltar que a palhada no SPD evitou intenso aquecimento do solo mesmo quando se fez o uso do filme de polietileno preto, embora tenha sido observado discreto aumento da temperatura no sistema de plantio direto com o polietileno, em relação aos tratamentos mantidos somente com a cobertura da palhada, o que demonstra a importância da cobertura vegetal sobre o aquecimento excessivo do solo, visto que a palha apresenta baixa condutividade térmica e alta refletividade dos raios solares (Silva et al., 2006). Maior temperatura do solo com uso de polietileno, em relação à cobertura do solo com material de origem vegetal, foi constatada por Ibarra-Jiménez et al. (2008) e Moura Filho (2009).

Os tratamentos sem capinas nos dois sistemas de plantio foram os que apresentaram temperaturas máximas e mínimas diárias mais baixas, especialmente no final do ciclo, devido ao crescimento das plantas infestantes, que promoveu intenso sombreamento do solo, impedindo que a radiação solar atingisse sua superficie (Figura 3A, B).

Analisando as temperaturas máximas e mínimas diárias durante todo o ciclo do pimentão, verifica-se que, apesar do intenso aquecimento durante o dia, o tratamento com cobertura com filme de polietileno no SPC apresentou queda na temperatura noturna, atingindo $29,77{ }^{\circ} \mathrm{C}$; quando se utilizou o filme de polietileno no SPD, as médias das temperaturas máxima e mínima diárias do solo foram de 34,5 e $31,76{ }^{\circ} \mathrm{C}$ (Figura 3B). Esse menor resfriamento do solo no plantio direto com filme de polietileno preto, em comparação ao plantio convencional, foi causado pela baixa condutividade térmica da palhada no SPD, que serviu como isolante térmico, diminuindo no período noturno a perda gradual de energia, acumulada pela incidência dos raios solares. Isso está em conformidade com Silva et al. (2002).

Durante o ciclo da cultura, à proporção em que ocorria decomposição da palhada no sistema de plantio direto capinado e com cobertura de polietileno preto, houve elevação da temperatura mínima do solo (Figura 3B), ao contrário do que se observou no sistema de plantio direto sem capina.

Houve grande variação da temperatura ao longo do dia, com a temperatura mínima ocorrendo por volta de $6 \mathrm{~h} 00 \mathrm{~min}$ e a máxima, em torno de $14 \mathrm{~h} 00 \mathrm{~min}$, para todos os tratamentos avaliados (Figura 4A), embora tenha sido verificado, nos tratamentos com cobertura morta (plantio direto), retardamento no aquecimento do solo pela manhã, em relação ao solo sem cobertura e com filme de polietileno no SPC. Segundo Trevisan et al. (2002), o sombreamento ocasionado pela palhada reduz a incidência de radiação e absorção de energia para evaporação devido à formação de uma massa de ar, que, por possuir menor condutividade térmica, retarda o aquecimento do solo.

Maiores amplitudes térmicas foram observadas no SPC, quando o solo foi coberto com filme de polietileno preto, onde as temperaturas mínimas e máximas foram de 28 e $40{ }^{\circ} \mathrm{C}$, e quando se utilizou a cultura mantida no limpo, onde as temperaturas minimas e máximas foram de 27 e $38,5{ }^{\circ} \mathrm{C}$, respectivamente (Figura 4A, B).

No período em que o solo foi mantido com algum tipo de cobertura vegetal - viva, no caso das plantas infestantes nos tratamentos onde não foram capinados nos dois sistemas de plantio, ou com cobertura morta, no caso da palhada no SPD - houve menor amplitude térmica, com temperaturas mínimas entre 26 e $28{ }^{\circ} \mathrm{C}$ e máximas entre 30 e $33{ }^{\circ} \mathrm{C}$ (Figura 4B).

Quando se fez controle das plantas daninhas por meio de capinas ou com filme de polietileno, as menores amplitudes térmicas durante o ciclo do pimentão ocorreram nos tratamentos plantio direto (Figura 4B). Segundo Ramos et al. (2009), a presença da palha sobre a superficie do solo, normalmente, atrasa a absorção de calor, reduzindo as oscilações térmicas entre o período diurno e o noturno. Menor variação térmica ao longo do dia é importante para evitar estresse na planta (Sampaio et al., 1999), desde que se atenda à faixa adequada para a cultura, ou seja, em condições de temperatura ambiente elevada e cultura sensivel podem ocorrer efeitos negativos sobre o crescimento e rendimento da cultura, embora não seja uma verdade absoluta. 

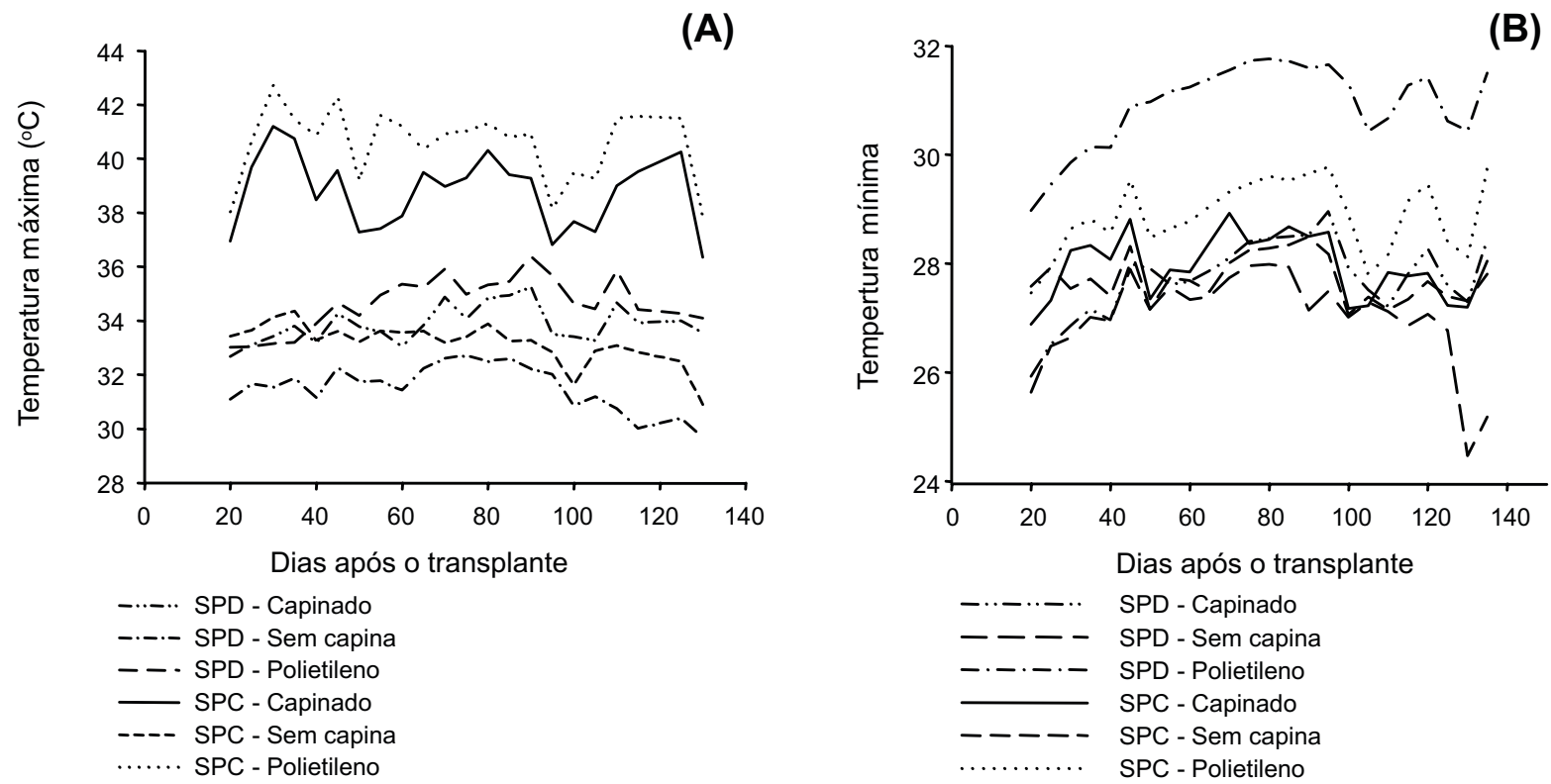

Figura 3 - Temperaturas máxima (A) e mínima (B) diárias do solo durante o ciclo da cultura do pimentão, em função de estratégias de manejo de plantas daninhas e coberturas do solo nos sistemas de plantio direto (SPD) e convencional (SPC). Mossoró-RN, UFERSA, 2010/2011.
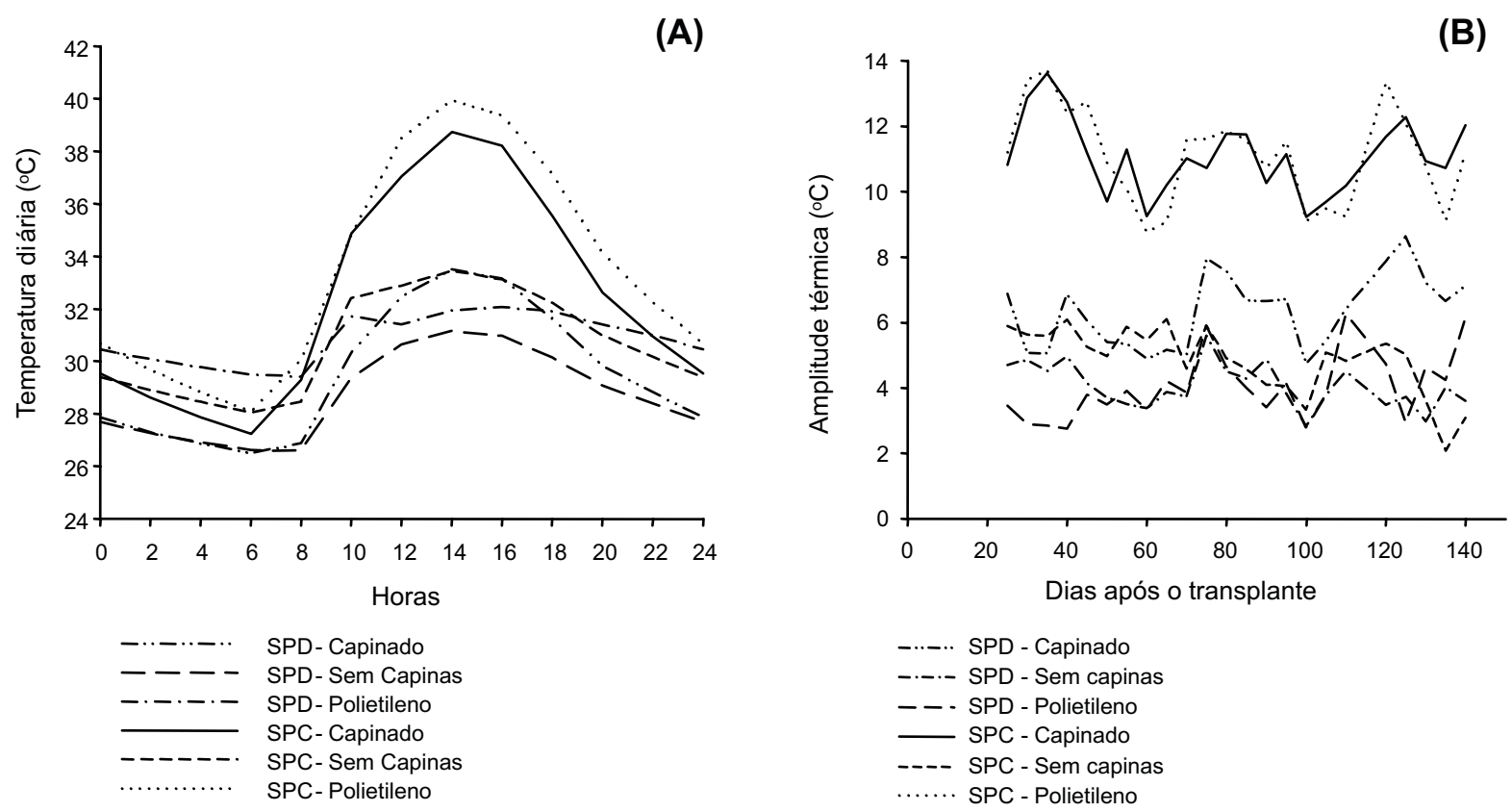

Figura 4 - Temperatura do solo ao longo do dia, no período de 20 a 30 dias após o transplante da cultura do pimentão (A) e amplitude térmica do solo ao longo do ciclo do pimentão (B), em função de estratégias de manejo de plantas daninhas e coberturas do solo nos sistemas de plantio direto (SPD) e convencional (SPC). Mossoró-RN, UFERSA, $2010 / 2011$.

Resultados semelhantes foram constatados por Brunini et al. (1976), avaliando o efeito da cobertura do solo no cultivo da cenoura. Esses autores verificaram que maior amplitude térmica a $5,0 \mathrm{~cm}$ de profundidade foi constatada quando se utilizou o filme de polietileno e com solo sem cobertura, ao passo que a menor amplitude e a maior temperatura 
média foram observadas quando se utilizou o filme de polietileno sobre a cobertura morta. Já o uso isolado da cobertura morta mostrou variação intermediária na amplitude.

Os tratamentos sem capinas nos dois sistemas de plantio, apesar de apresentarem as menores temperaturas do solo (Figura 3B), dentro da faixa mais adequada para a cultura, proporcionaram os menores valores na produtividade de frutos, em razão da interferência exercida pelas plantas daninhas (Figura 2A, B). É provável que a elevação da temperatura do solo no sistema de plantio convencional capinado e com cobertura com polietileno preto tenha influenciado negativamente o desenvolvimento da cultura do pimentão, ocasionando redução substancial na produtividade de frutos, ao passo que o tratamento mantido sem infestação de plantas daninhas no sistema de plantio direto e com menor temperatura ao longo do ciclo do pimentão destacou-se em relação aos demais, apresentando produtividade comercial e total de 36,28 e 38,41 $\mathrm{t} \mathrm{ha}^{-1}$, respectivamente (Tabela 1). Segundo Pádua et al. (1984) e Lorentz (2004), durante o florescimento a temperatura diurna do solo deve estar entre 21 e $27^{\circ} \mathrm{C}$ e as noturnas entre 18 e $20{ }^{\circ} \mathrm{C}$, por favorecer a boa formação dos frutos. Temperatura do solo acima de $30^{\circ} \mathrm{C}$ reduz o crescimento radicular e provoca o abortamento de flores.

Queiroga et al. (2002), trabalhando com pimentão, verificaram que a cobertura do solo com palha de carnaúba propiciou redução significativa na infestação de plantas daninhas, em relação ao solo sem cobertura, e também influenciou positivamente a produção de pimentão, visto que essa cobertura reduz a elevação da temperatura do solo, diminuindo as perdas de água por evaporação.

Apesar do efeito negativo do filme de polietileno na produção de pimentão neste trabalho, que ocorreu provavelmente em função da temperatura ambiente elevada, cujas médias e máxima diária oscilaram em torno de 28 e $35^{\circ} \mathrm{C}$ (Figura 1A), e da sensibilidade da cultura à temperatura do solo elevada, a utilização dessa técnica pode ser benéfica em condições ambientais com temperatura mais amena e/ ou cultura adaptada à temperatura elevada. Brunini et al. (1976), em condições de temperatura média diária do solo inferior a $20^{\circ} \mathrm{C}$, verificaram efeito benéfico da redução da amplitude térmica e da elevação da temperatura média diária pela combinação de filme de polietileno sobre cobertura morta na produtividade da cenoura. Efeitos benéficos da cobertura do solo com filme de polietileno no sistema de plantio direto foram constatados por Tomaz (2008) sobre a produtividade do melão e por Silva (2010) para a cultura de melancia, devido ao fato de essas culturas sombrearem totalmente o solo após 30 dias do plantio e tolerarem temperatura do solo mais elevada do que a cultura do pimentão.

Diante do exposto, conclui-se que os tratamentos mantidos com cobertura morta no sistema de plantio direto ou com plantas

Tabela 1 - Produtividade comercial e total $\left(\mathrm{t} \mathrm{ha}^{-1}\right)$ da cultura do pimentão, em função de estratégias de manejo de plantas daninhas nos sistemas de plantio direto (SPD) e plantio convencional (SPC). Mossoró-RN, UFERSA, 2011

\begin{tabular}{|c|l|c|c|}
\hline \multirow{2}{*}{ Sistema de plantio } & \multicolumn{1}{|c|}{ Sistema de manejo } & Produtividade comercial & Produtividade total \\
\cline { 2 - 4 } & & \multicolumn{2}{|c|}{$\left(\mathrm{t} \mathrm{ha}^{-1}\right)$} \\
\hline \multirow{3}{*}{ Plantio direto } & Polietileno preto & $6,04 \mathrm{bA}$ & $10,42 \mathrm{bA}$ \\
\cline { 2 - 4 } & Capinado & $36,28 \mathrm{aA}$ & $38,41 \mathrm{aA}$ \\
\cline { 2 - 4 } & Sem capina & $1,83 \mathrm{bA}$ & $1,93 \mathrm{cA}$ \\
\hline Média & & 14,72 & $8,45 \mathrm{aA}$ \\
\hline \multirow{3}{*}{ Plantio convencional } & Polietileno preto & $7,06 \mathrm{aA}$ & $12,18 \mathrm{aB}$ \\
\hline & Capinado & $9,86 \mathrm{aB}$ & $0,78 \mathrm{bA}$ \\
\hline & Sem capina & $0,78 \mathrm{bA}$ & 7,13 \\
\hline Média & & 5,90 & 22,67 \\
\hline CV $(\%)$ & & 25,71 & \\
\hline
\end{tabular}

Nas colunas, letras minúsculas comparam as estratégias de manejo de plantas daninhas dentro de cada sistema de plantio, e letras maiúsculas comparam sistemas de plantio, dentro de cada estratégia de manejo de plantas daninhas, pelo teste de Tukey $(\mathrm{p} \leq 0,05)$. 
daninhas nos sistemas de plantio direto e convencional apresentaram menor aquecimento e amplitude térmica do solo em relação ao solo mantido no limpo com capinas ou coberto com filme de polietileno no sistema de plantio convencional; a temperatura elevada nesses tratamentos resultou em queda na produtividade. A maior produtividade de pimentão foi obtida no sistema de plantio direto com capinas. A interferência das plantas daninhas nos tratamentos sem capinas resultou em redução de 94,95 e $92,10 \%$ da produtividade comercial nos sistemas de plantio direto e convencional, respectivamente.

\section{LITERATURA CITADA}

ALLEN, R. G. et al. Evapotranspiration del cultivo: guías para la determinación de los requerimentos de agua de los cultivos. Roma: FAO, 2006. 298 p.

(Estúdio FAO Riego y Drenaje, 56)

BONANOMI, G. et al. Soil solarization with biodegradable materials and its impact on soil microbial communities. Soil Biol. Biochem., v. 40, n. 8, p. 1989-1998, 2008.

BRUNINI O. et al. Estudo micrometeorológico com cenouras (Var. Nantes) II - Influência da temperatura do solo. Bragantia [online]. v. 35, n. 1, p. 49-54, 1976.

CARMO FILHO, F.; OLIVEIRA, O. F. Mossoró: um município do semi-árido nordestino, caracterização climática e aspecto florístico. Mossoró: ESAM, 1995. 62 p. (Coleção Mossoroense, série B).

CARVALHO, J. E. et al. Cobertura morta do solo no cultivo de alface cv. Regina, em Ji-Paraná/RO.

Ci. Agrotec., v. 29, n. 5, p. 935-939, 2005.

EMPRESA BRASILEIRA DE PESQUISA AGROPECUÁRIA - EMBRAPA. Sistema brasileiro de classificação de solos. Rio de Janeiro: Embrapa/Centro Nacional de Pesquisa do Solo, 2006. 306 p.

FURLANI, C. E. A. et al. Temperatura do solo em função do preparo do solo e do manejo da cobertura de inverno. R. Bras. Ci. Solo, v. 32, n. 1, p. 375-380, 2008

GASPARIM, E. et al. Temperatura no perfil do solo utilizando duas densidades de cobertura e solo nu. Acta Sci. Agron., v. 27, n. 1, p. 107-115, 2005

IBARRA-JIMÉNEZ, L. et al. Photosynthesis, soil temperature and yield of cucumber as affected by colored plastic mulch. Acta Agric. Scandinavica Section B - Soil Plant Sci., v. 58, n. 4, p. 372-378. 2008.
LEVIEN, R. et al. Temperaturas do solo e do ar durante o desenvolvimento do milho em diferentes condições de manejo do solo. In: CONGRESSO BRASILEIRO DE ENGENHARIA AGRÍCOLA, 34., Canoas, 2005. Anais... Porto Alegre: Associação Brasileira de Engenharia Agrícola, 2005. CD ROM

LORENTZ, L. H. Variabilidade da produção de frutos de pimentão em estufa plástica relacionada com técnicas experimentais. 2004. 82 f. Dissertação (Mestrado em Melhoramento Genético) - Universidade Federal de Santa Maria, Santa Maria, 2004.

MOURA FILHO, E. R. Cobertura do solo e épocas de capina nas culturas de alface e beterraba. 2009. $67 \mathrm{f}$. Tese (Doutorado em Fitotecnia) - Universidade Federal Rural do Semi-Árido, Mossoró, 2009.

PÁDUA, J. G. et al. Efeitos climáticos sobre pimentão e pimenta. Inf. Agropec., v. 10, n. 1, p.11-13, 1984

QUEIROGA, R. C. F. et al. Utilização de diferentes materiais como cobertura morta do solo no cultivo de pimentão. Hortic. Bras., v. 20, n. 3, p. 416-418, 2002.

RAMOS, N. P. et al. Girassol: emergência e crescimento inicial de plantas sob resíduos de cana-de-açúcar.Ci. Rural, v. 39, n. 1, p. $45-51,2009$.

RESENDE, F. V. et al. Uso de cobertura morta vegetal no controle da umidade e temperatura do solo, na incidência de plantas invasoras e na produção da cenoura em cultivo de verão.Ci. Agrotéc., v. 29, n. 1, p. 100-105, 2005.

RIBEIRO A. C. et al. Recomendações para o uso de corretivos e fertilizantes em Minas Gerais $5^{\text {a }}$ Aproximação. Viçosa, MG: Comissão de Fertilidade do Solo do Estado de Minas Gerais - CFSEMG, 1999. $359 \mathrm{p}$.

SAMPAIO, Q. A. et al. Resposta do tomateiro à fertirrigação potássica e cobertura plástica do solo. Pesq. Agropec. Bras., v. 34, n. 1, p. 21-30, 1999.

SILVA, M. A. A. et al. Influência da cultura do pimentão (Capsicum annuиm L.) nos elementos ambientais em ambiente protegido. Irriga, v. 7, n. 3, p. 230-240, 2002 .

SILVA, M. G. O. Cultivo da melancia nos sistemas de plantio direto e convencional. 2010, 50 f. Dissertação (Mestrado em Fitotecnia) - Universidade Federal Rural do Semi-Árido, Mossoró, 2010.

SILVA, V. R. et al. Variação na temperatura do solo em três sistemas de manejo na cultura do feijão. R. Bras. Ci.

Solo, v. 30, n. 3, p. 391-399, 2006. 
SOUZA, E. R. et al.Variabilidade espacial da umidade do solo em Neossolo Flúvico. R. Bras. Rec. Hídricos, v. 13, n. 2 , p. 177-187, 2008.

TEÓFILO, T. M. S. et al. Eficiência no uso da água e interferência de plantas daninhas no meloeiro cultivado nos sistemas de plantio direto e convencional. Planta Daninha, (prelo...).
TOMAZ, H. V. Q. Manejo de plantas daninhas, crescimento e produtividade do meloeiro em sistemas de plantio direto e convencional. 2008. 67 f. Dissertação (Mestrado em Fitotecnia) - Universidade Federal Rural do Semiárido, Mossoró, 2008.

TREVISAN, R. et al. Variação da amplitude térmica do solo em pomar de pessegueiro cultivado com aveia preta (Avena sp.) e em sistema convencional. R. Bras. Agroci., v. 8, n. 2, p. 155-157, 2002. 